\title{
Modeling of the Repository Behavior of TRISO Fuel
}

prepared by

Nuclear Engineering Division

Argonne National Laboratory 


\section{About Argonne National Laboratory}

Argonne is managed by The University of Chicago for the U.S. Department of Energy under contract W-31-109-Eng-38. The Laboratory's main facility is outside Chicago, at 9700 South Cass Avenue, Argonne, Illinois 60439. For information about Argonne and its pioneering science and technology programs, see www.anl.gov.

\section{Availability of This Report}

This report is available, at no cost, at http://www.osti.gov/bridge. It is also available on paper to the U.S. Department of Energy and its contractors, for a processing fee, from:

U.S. Department of Energy

Office of Scientific and Technical Information

P.O. Box 62

Oak Ridge, TN 37831-0062

phone (865) 576-8401

fax (865) 576-5728

reports@adonis.osti.gov

\section{Disclaimer}

This report was prepared as an account of work sponsored by an agency of the United States Government. Neither the United States Government nor any agency thereof, nor The University of Chicago, nor any of their employees or officers, makes any warranty, express or implied, or assumes any legal liability or responsibility for the accuracy, completeness, or usefulness of any information, apparatus, product, or process disclosed, or represents that its use would not infringe privately owned rights. Reference herein to any specific commercial product, process, or service by trade name, trademark, manufacturer, or otherwise, does not necessarily constitute or imply its endorsement, recommendation, or favoring by the United States Government or any agency thereof. The views and opinions of document authors expressed herein do not necessarily state or reflect those of the United States Government or any agency thereof, Argonne National Laboratory, or The University of Chicago. 


\section{Modeling of the Repository Behavior of TRISO Fuel}

by

E.E.Morris and T.H.Bauer

Nuclear Engineering Division, Argonne National Laboratory

September 29,2005

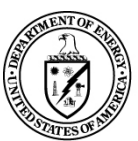




\section{Modeling of the Repository Behavior of TRISO Fuel (Milestone 4295 for Work Package A0403K11: Rev. 1)}

By

Edgar E. Morris and Theodore H. Bauer

Nuclear Engineering Division, Argonne National Laboratory

October 3, 2005

\section{Introduction}

This report satisfies Milestone 4295 for Work Package A0403K11. The long-term behavior of TRISO nuclear reactor fuel in a geologic repository is examined in terms of its durability and thermal impact. The TRISO fuel concept, under development at General Atomics[1] involves embedding fissile uranium and/or actinides in a carbonaceous material as shown in Fig. 1. In the concept, fuel kernels containing fissile material are surrounded with a porous carbon buffer and coated with inner and outer pyrocarbon layers separated with a $\mathrm{SiC}$ layer. The fuel particles are then imbedded in a graphite compact and the compacts placed in fuel channels drilled in fuel assembly blocks as shown in the lower right-hand corner of the figure. Dimensions are listed in Table 1. Available data on the degradation of the carbonaceous materials in an aqueous environment is reviewed. A model accounting for waste package failure and the resulting degradation of the waste forms is used to evaluate the potential for the long-

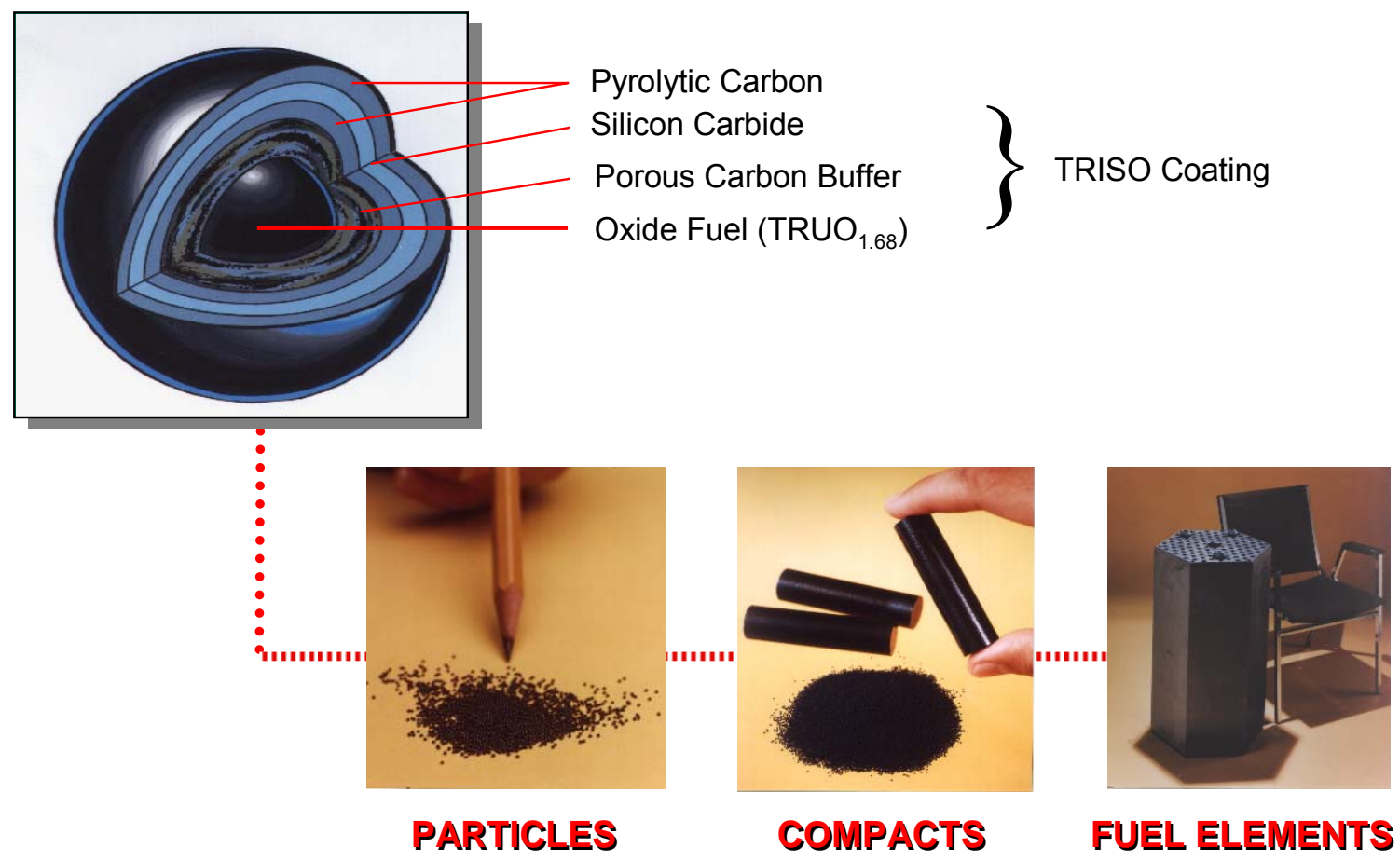

Fig. 1. TRISO fuel concept showing the fuel particles, fuel compacts, and fuel assembly blocks. 
Table 1

DB-MHR fuel assembly, fuel compact, and particle dimensions.

\begin{tabular}{|c|c|c|}
\hline \multicolumn{3}{|c|}{ Fuel Particles } \\
\hline & Kernel Radius, $\mu \mathrm{m}$ & 175 \\
\hline & Buffer Thickness, $\mu \mathrm{m}$ & 100 \\
\hline & Inner Pyrocarbon Coating Thickness, $\mu \mathrm{m}$ & 35 \\
\hline & SiC Coating Thickness, $\mu \mathrm{m}$ & 35 \\
\hline & Outer Pyrocarbon Coating Thickness, $\mu \mathrm{m}$ & 40 \\
\hline \multicolumn{3}{|c|}{ Fuel Compacts } \\
\hline & Diameter, mm & 12.45 \\
\hline & Height, mm & 49.3 \\
\hline \multicolumn{3}{|c|}{ Hexagonal Fuel Assembly Blocks (Elements) } \\
\hline & Flat to Flat, mm & 360 \\
\hline & Height, mm & 790 \\
\hline & Graphite Thickness Between Fuel and Coolant Channels, mm & 4.5 \\
\hline
\end{tabular}

term sequestration of radionuclides from spent TRISO fuel in the Yucca Mountain Repository. Finally, thermal analyses of decay heat assess the potential benefits in repository space utilization from recycling actinides from PWR spent fuel as very high burnup TRISO fuel.

Experimental data on the aqueous dissolution of carbonaceous materials is relatively sparse and in some cases is based on measurements carried out at temperatures much higher than would be expected in the repository. In addition, the degree to which the aqueous solutions used in the measurements are representative of Yucca Mountain groundwater is uncertain. However, the available dissolution rate data are generally two or more orders of magnitude lower than the Yucca Mountain Project's dissolution model for borosilicate glass. Model calculations show that if the observed rates are applicable to the Yucca Mountain environment, directly disposed TRISO fuel has the potential to prevent significant release of radionuclides to the environment for several million years.

A scheme was examined where actinide elements recovered from $\sim 77$ MT of spent PWR fuel were used to manufacture 1 MT of TRISO fuel for a high-burnup recycle in a Deep Burn Modular Helium Reactor (DB-MHR). PWR process waste and spent DB-MHR fuel would be disposed in the Yucca Mountain Repository. Thermal performance computations show that the space utilization benefit of this recycle scheme would potentially be in the range of 1.7 to 1.8 as compared to generating the same amount of nuclear energy only in PWRs with direct disposal of the spent fuel.

\section{Dissolution of Carbonaceous Waste Forms}

Experimental data on the dissolution of $\mathrm{SiC}$, pyrolytic carbon, and graphite have been found for several aqueous solutions [3-7]. The earliest results [5] were for materials in deionized water at temperatures higher than $200{ }^{\circ} \mathrm{C}$. More recent results have been reported by researchers in Europe and are found in viewgraph presentations [6, 7]. The experiments were carried out in 


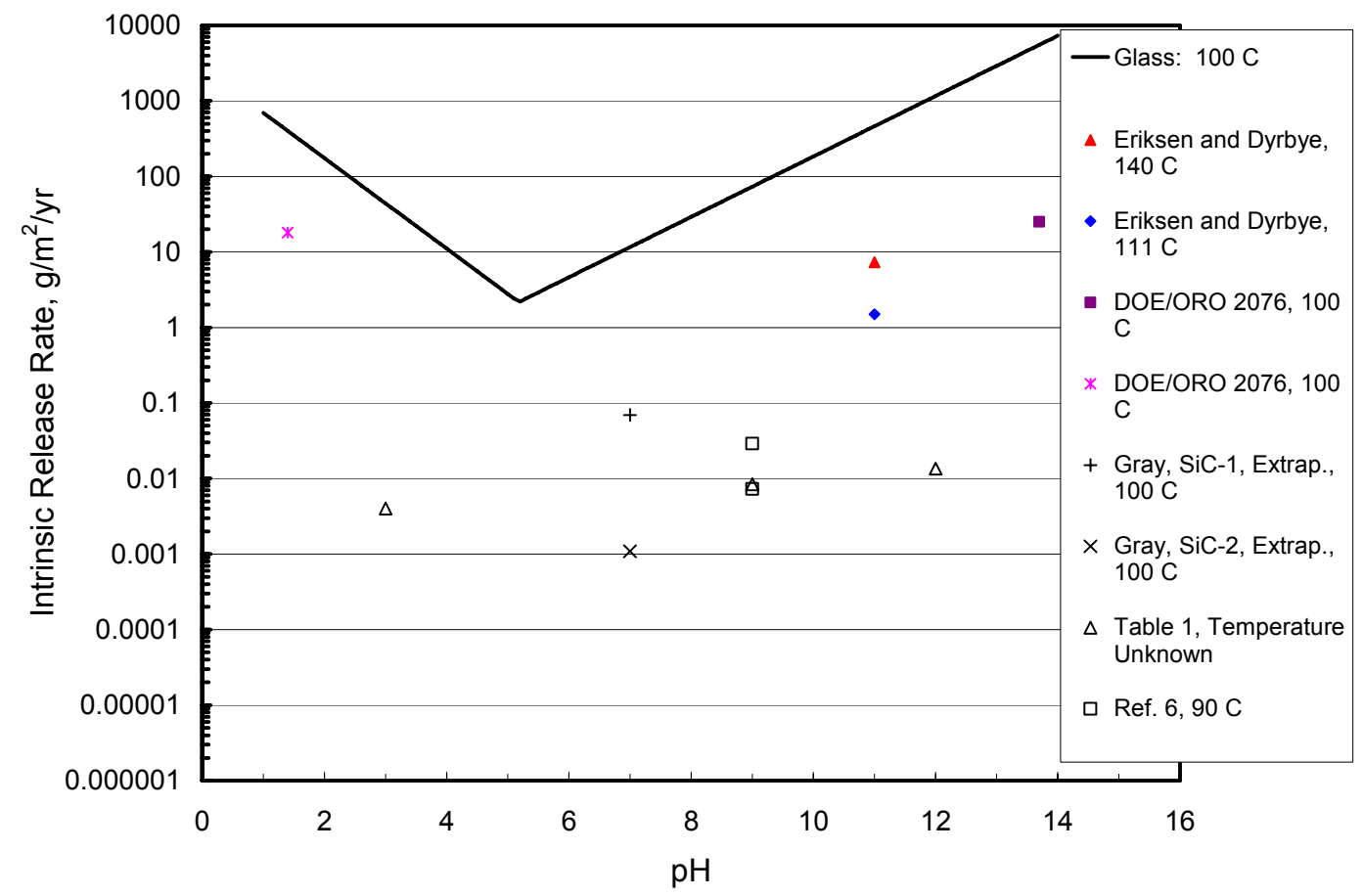

Fig. 2. Comparison of $\mathrm{SiC}$ dissolution rates with rates for borosilicate glass.

deionized water, granite water, clay pore water, and various brines. Temperatures in the experiments are close to the range of interest for the Yucca Mountain Repository.

Figure 2 shows data for the dissolution of $\mathrm{SiC}$ in solutions covering a wide range of $\mathrm{pH}$. (Values for highly concentrated acidic and basic solutions from Ref. 4 were arbitrarily set near 1 and 14.) The v-shaped curve shows dissolution rates at $100{ }^{\circ} \mathrm{C}$ for borosilicate glass as modeled by the Yucca Mountain Project[2]. Data from Gray[5] were extrapolated into the temperature range considered in Refs. 6 and 7 using the Arrhenius equation and the activation energies reported. The scatter of the measured data in Fig. 2 is roughly consistent with a v-shaped function of $\mathrm{pH}$ similar to that indicated for glass. Reference 6 also compared leach rates for irradiated and unirradiated samples of SiC. Their results show higher leach rates immediately after irradiation but that after 72 hours irradiation, the long-term leach rates leach rates in irradiated and unirradiated samples are similar. Data shown in Ref. 7 also indicate higher leach rates for irradiated $\mathrm{SiC}$; however, no time frame was identified.

Dissolution rates for graphite and two pyrocarbon samples in deionized water under a cover gas of air are reported by Gray[5]. Figure 3 shows Gray's results for graphite. Measurements were carried out at temperatures of 300,250 , and $200{ }^{\circ} \mathrm{C}$. These data points are shown near the upper left-hand corner of the graph. The solid line represents a regression line used to determine the parameters in the Arrhenius equation. Extrapolation of Gray's results to lower temperatures using the Arrhenius equation is indicated by the heavier dashed line. Estimated uncertainties in the extrapolation are indicated by the lighter dashed lines. The extrapolations indicate that the expected value of the dissolution rate at $30{ }^{\circ} \mathrm{C}$ is $9.8 \times 10^{-6}$ $\mathrm{g} / \mathrm{m}^{2} / \mathrm{yr}$. Using the "bounding" extrapolations, the upper limit can be estimated to be $1.8 \times 10^{-5}$ 


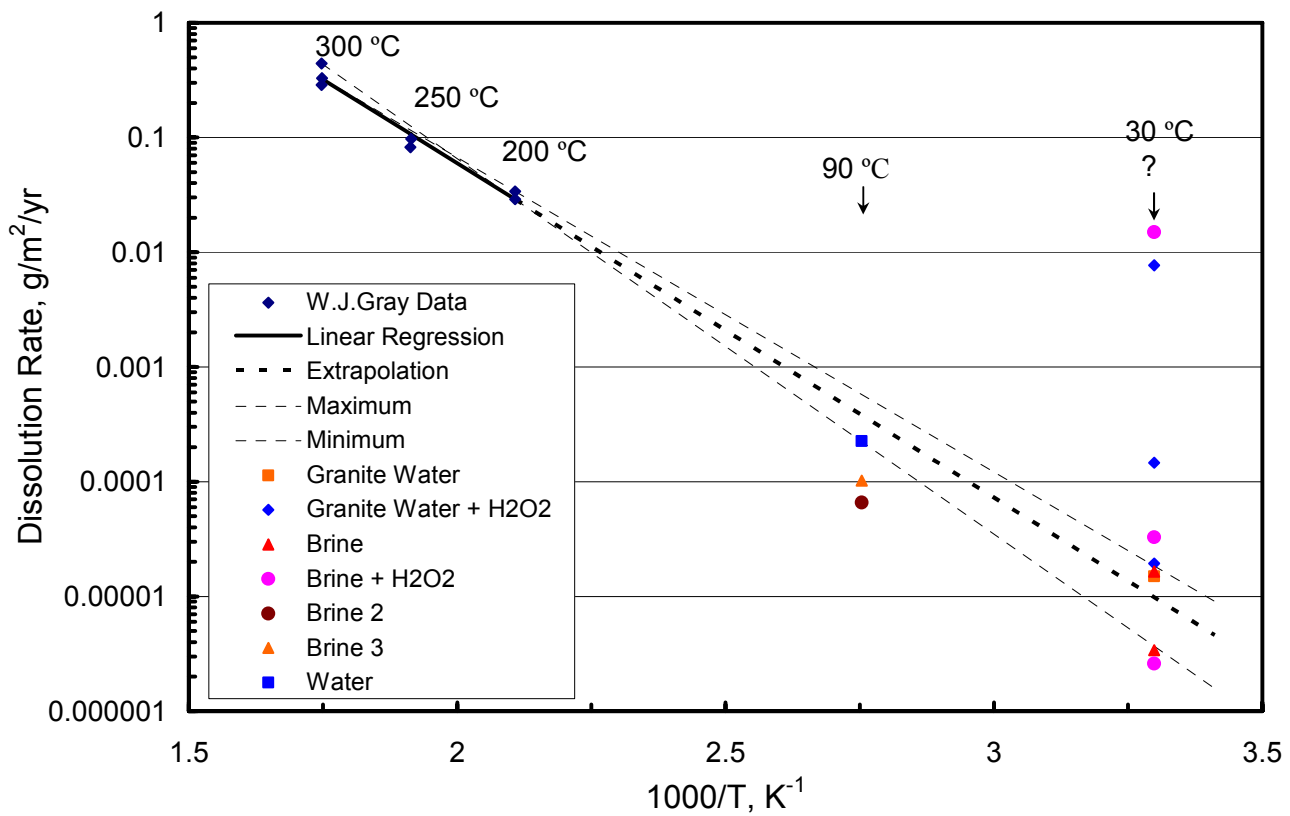

Fig. 3. Arrhenius plot of dissolution rates for graphite from Refs. 5, 6, and 7.

$\mathrm{g} / \mathrm{m}^{2} / \mathrm{yr}$ and the lower limit $3.7 \times 10^{-6} \mathrm{~g} / \mathrm{m}^{2} / \mathrm{yr}$. Data from Refs. 6 and 7 are also shown on the plot. The placement of data from Ref. 6 on the figure at $30^{\circ} \mathrm{C}$ is uncertain as indicated by the question mark on the graph. Data from Ref. 7 at $90{ }^{\circ} \mathrm{C}$ agree well with the Arrhenius extrapolation of Gray's data.

Data from Ref. 6 are also shown in Fig. 4 to show an observed decline in the dissolution rate with time. Two possible explanations might be that dissolved oxygen in the solution is used up with the passage of time or that some kind of passivation mechanism is acting. This time dependence accounts for much of the scatter shown in Fig. 3 for the data points at $30^{\circ} \mathrm{C}$.

Gray also presents measurements for the dissolution rates of two samples of pyrocarbon in deionized water at 200,250 , and $300{ }^{\circ} \mathrm{C}$. Extrapolation of these measurements using the Arrhenius equation from to a temperature of $30{ }^{\circ} \mathrm{C}$ results in a dissolution rate for the first sample nearly a factor of ten lower than the result for graphite shown in Fig. 3 and for the second sample approximately a factor of ten higher than the graphite result. Dissolution rates shown in Ref 7 for pyrocarbons in deionized water and in brine solutions show rates that appear to be much smaller than $4 \times 10^{-4} \mathrm{~g} / \mathrm{m}^{2} / \mathrm{yr}$. With the exception of one of the samples considered by Gray, the dissolution rate for pyrocarbons appears to be larger than for graphite under similar thermochemical conditions. Taken together, these data indicate an uncertainty in the pyrocarbon dissolution rate of several orders of magnitude.

An overview of the results discussed above implies that $\mathrm{SiC}$ will likely have a higher dissolution rate than pyrolytic carbon and that pyrolytic carbon dissolution rates are likely to be somewhat larger than graphite dissolution rates. Confirmatory experiments are needed. 


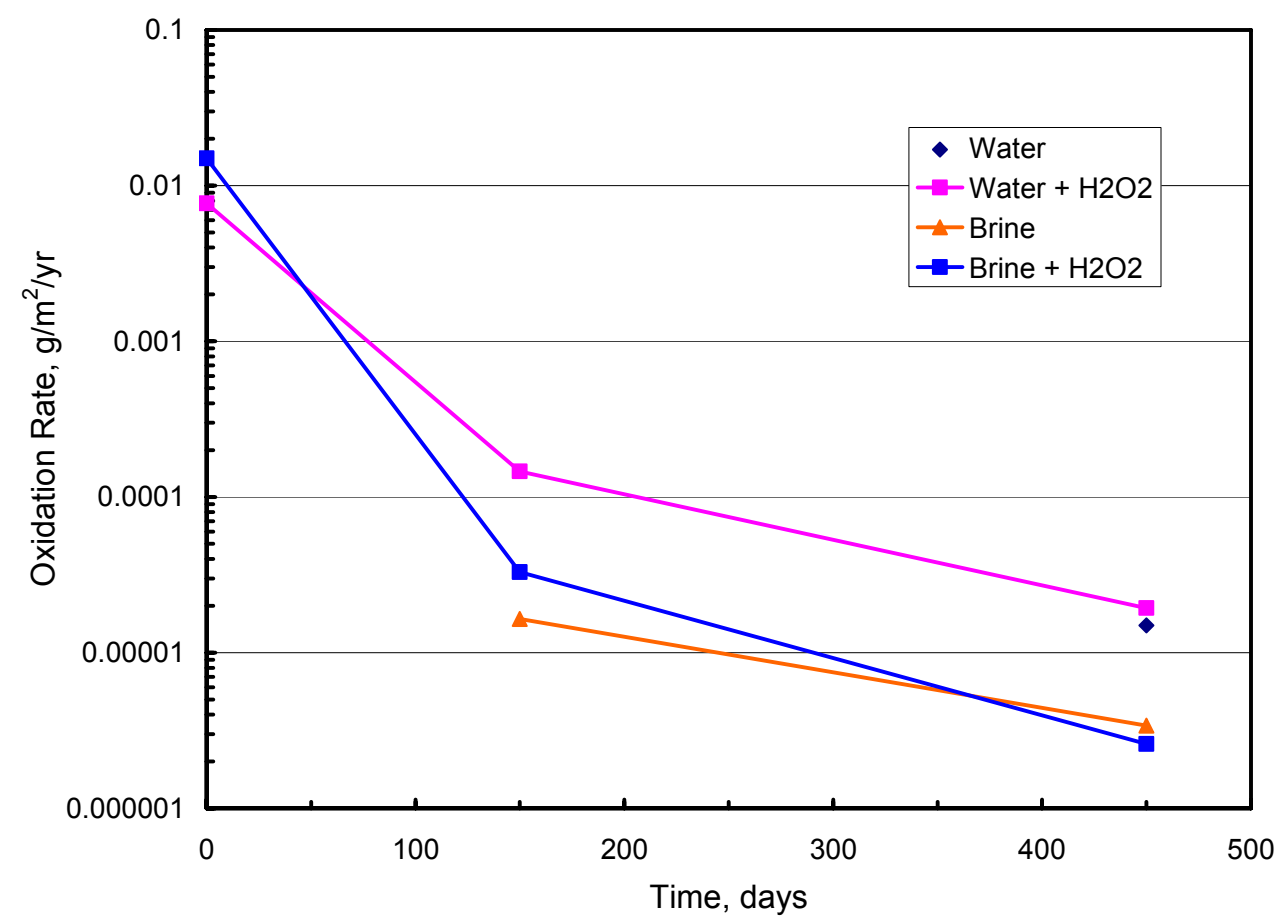

Fig. 4. Oxidation rates from Ref. 6.

\section{TRISO Fuel Degradation Modeling}

A computer model was developed to estimate the rate at which the fuel kernels in the TRISO fuel particle might be exposed to the repository environment. The model makes use of a simplified representation of the waste package failure rate as a function of time in the Yucca Mountain performance assessment described in Ref. 1. Once the waste package is breached, the calculation assumes that water will be present in the coolant channels of the fuel assembly. The rate at which compacts are exposed to groundwater is simply the rate at which waste packages fail but with a time delay equal to the time required to dissolve the graphite between the coolant channels and the fuel channels. In the event that compacts are placed in the waste package after removal from the fuel assembly blocks or that the fuel channels are not sealed, this time delay is set to zero. TRISO fuel particles are exposed to the ground water at the rate at which the fuel compacts dissolve. The fuel kernels are exposed to ground water at the same rate as the compact dissolution rate but with a time delay equal to the time required to dissolve the outer pyrocarbon layer, the $\mathrm{SiC}$ layer, and the inner pyrocarbon layer. No credit is taken for the presence of the carbon buffer layer between the inner pyrocarbon layer and the fuel kernel.

The model sketched in the foregoing paragraph has been used to explore the implications of the dissolution rate measurements described in the previous section. Results from calculations using the model are shown in Figs. 5, 6, and 7. In Fig. 5, it is assumed that the fuel compacts and the TRISO fuel particle coatings do not protect the fuel kernels once the graphite between the coolant channels and the fuel channels in the fuel assembly blocks is corroded or dissolved. This was accomplished by setting the fuel compact dissolution rate to a fairly large value and the 
time required to dissolve the coatings in the TRISO fuel particles to zero. Except for being shifted by the time required to dissolve the graphite between the coolant and fuel channels, the temporal shape of the curve indicating the fraction of fuel kernels exposed to water is the same as the temporal shape of the number of failed waste packages.

It is uncertain whether or not graphite in the fuel assembly blocks is permeable or impermeable. Results in Fig. 5 indicate that if graphite dissolution rates are about $10^{-3} \mathrm{~g} / \mathrm{m}^{2} / \mathrm{yr}$ or lower, the assembly blocks have the potential to keep water away from the fuel compacts and fuel particles for several million years or more. This assumes that the blocks are not porous. However, Ref. 7 indicates that neutron irradiation increases open porosity in graphite. Richards[8] states that the fuel assembly blocks are porous and permeable.

Figure 6 shows the fraction of fuel kernels exposed to groundwater in the event that only the fuel compacts provide protection. In these cases, the time required to dissolve graphite between coolant and fuel channels in fuel assembly blocks and the time required to dissolve the coatings on the TRISO fuel particles were set to zero. Under these conditions, the fuel compacts begin to dissolve immediately and some fraction of the fuel kernels are immediately exposed to groundwater. The curves in Fig. 6 show, however, that if dissolution rates for the fuel compacts are $10^{-4} \mathrm{~g} / \mathrm{m}^{2} / \mathrm{yr}$ or less, the fraction of fuel kernels exposed will be less than $3 \%$ for the first million years. If the rate is an order of magnitude smaller, it may be possible to keep the fraction below $3 \%$ for 10 million years.

In Fig. 7, it is assumed that neither the fuel assembly blocks nor the fuel compacts offer protection from groundwater. This required setting the time for dissolving the graphite between the coolant and fuel channels to zero and the dissolution rate for the fuel compacts to a large value. The results in the figure show that if the coating dissolution rates are $10^{-4} \mathrm{~g} / \mathrm{m}^{2} / \mathrm{yr}$ or less the coatings could potentially protect the fuel kernels from groundwater for more than 2 million years. Data referred to in the preceding section suggests that the dissolution rate for SiC might be larger than the rate for pyrolytic carbon. Some additional parametric calculations indicates even if the $\mathrm{SiC}$ provided no protection, the pyrocarbon layers could protect the fuel kernels for more than 1 million years if the rate is $10^{-4} \mathrm{~g} / \mathrm{m}^{2} / \mathrm{yr}$. If the rate were more $10^{-5} \mathrm{~g} / \mathrm{m}^{2} / \mathrm{yr}$, the pyrocarbon coatings, without help from $\mathrm{SiC}$, could prevent water contact with the fuel kernels for more than 10 million years. With this latter rate, a single pyrocarbon layer could protect the kernels for nearly 6 million years. If the $\mathrm{SiC}$ dissolution rate were $10^{-4} \mathrm{~g} / \mathrm{m}^{2} / \mathrm{yr}$ the SiC layer could protect the fuel kernel for more than 1 million years and if it were $10^{-5} \mathrm{~g} / \mathrm{m}^{2} / \mathrm{yr}$, it could protect the kernel for more than 10 million years.

\section{Repository Utilization}

A potential benefit to repository utilization was estimated for a recycling strategy in which spent nuclear fuel, irradiated to a burnup of $51 \mathrm{GWd} / \mathrm{MTIHM}$ in a PWR, is processed to remove $99.9 \%$ of the actinides and $97 \%$ of the fission products $\mathrm{Cs}, \mathrm{Sr}$, and Eu. Removed actinides are then used to manufacture TRISO recycle fuel which is irradiated to a burnup of 546 GWd/MTIHM in the DB-MHR. For the recycle scheme considered here, 77 MT of spent PWR fuel is required to manufacture $1 \mathrm{MT}$ of the TRISO fuel for the DB-MHR. Repository benefit can be estimated by comparing the repository space required for direct disposal of the spent PWR fuel with the space required for PWR process waste plus the directly-disposed spent fuel from the DB-MHR. Preliminary reactor physics analyses for this recycling scheme were carried 
out by T. K. Kim[9]. Comparison was made on the basis of equivalent thermal energy production and again on the basis of equivalent electrical energy production. (On the basis of equivalent thermal energy production the mass of spent PWR fuel required to produce the same energy as 77 MTIHM of PWR fuel and 1 MTIHM of DB-MHR fuel is 88 MTIHM while on the basis of electrical energy production, it is 93 MTIHM.)

Three separate thermal analyses were performed to determine the maximum drift loading for drifts containing the estimated decay heat from: (1) spent PWR fuel, (2) processed waste from spent PWR fuel, and (3) spent DB-MHR fuel. The temperature limits used to constrain the drift loading are $200{ }^{\circ} \mathrm{C}$ at the drift wall and the water boiling temperature $\left(96^{\circ} \mathrm{C}\right)$ at a point midway between drifts. Figures 4, 5, and 6 show the results from these calculations. It is observed that for all three waste forms, the temperature at a point midway between repository drifts determines the maximum loading. The figure labels indicate maximum loadings in terms of $\mathrm{MTHM} / \mathrm{m}$ or metric tons of heavy-metal fuel per meter of drift length. Multiplying these numbers by fuel burnup (e.g., GWd/MTHM) converts the loading-limit basis from mass units to energy units. For a given basis (mass or energy), the inverse of the loading limit yields a measure of the repository space required. Weighted (mass or energy) averages of these bases yields the space needed for each strategy. Computed repository space requirements are broken down into components shown in the last two columns of Table 2. In the recycle case, we observe that the amount of space required by the PWR process waste is small compared to the space required by the spent DB-MHR fuel (due to the fact that a large fraction of recycled heatgenerating actinides are carried over to the spent DB-MHR fuel). However, when combined together, a small net benefit results relative to spent PWR fuel. On the basis of equivalent thermal energy the net benefit was found to be 1.7 and on the basis of equivalent electrical energy 1.8 .

As noted in the preceding paragraph, Table 2 shows that the amount of space required by the PWR process waste is small compared to the space required by the spent DB-MHR fuel. At this point it is not known whether the DB-MHR fuel would be disposed in the fuel assembly blocks or whether the compacts would be punched out and sent to the repository without the blocks. In the case in which the fuel is sent as assembly blocks, and assuming the blocks are placed in a waste package the size of the 21-PWR waste packages, one can estimate that the drift loading would be about $0.015 \mathrm{MTIHM} / \mathrm{m}$. This result is shown in the second column of Table 2 . As indicated in the table, it would provide a repository benefit of 1.1. Thus, if fuel assembly blocks are disposed, the repository benefit might be limited by the size of the waste packages. If the compacts are disposed without the fuel assembly blocks, then the 21-PWR waste packages would permit a drift loading of $0.57 \mathrm{MTIHM} / \mathrm{m}$ and this would have a potential repository benefit of 4.2. This result, shown in column 3 of Table 2, would, however, violate the temperature limits referred to in the preceding paragraph.

\section{Conclusions}

Existing degradation measurements of carbonaceous materials relevant to TRISO fuel cover a wide variety of test solution environments. Although data is sparse and confirmatory experiments are needed to fully assess its applicability, the temperature and $\mathrm{pH}$ range covered likely spans solution environments encountered in a geologic repository. 
Table 2

Benefit of combined PWR/DB-MHR strategy to direct disposal of spent PWR fuel.

\begin{tabular}{|c|c|c|c|c|}
\hline \multirow[b]{2}{*}{ Quantity } & \multicolumn{2}{|c|}{ Based on Geometry } & \multirow{2}{*}{$\begin{array}{c}\text { Based } \\
\text { on } \\
\text { Thermal } \\
\text { Energy }\end{array}$} & \multirow[b]{2}{*}{$\begin{array}{l}\text { Based on } \\
\text { Electrica } \\
1 \text { Energy }\end{array}$} \\
\hline & $\begin{array}{c}\text { Fuel } \\
\text { Assembly } \\
\text { Blocks } \\
\end{array}$ & $\begin{array}{c}\text { Compacts } \\
\text { Only }\end{array}$ & & \\
\hline Drift loading for PWR fuel, MTIHM/m & -- & -- & 1.15 & 1.15 \\
\hline Drift loading for PWR process waste, MTIHM/m & -- & -- & 110 & 110 \\
\hline Drift loading for GT-MHR fuel, MTIHM/m & 0.015 & 0.057 & 0.0225 & 0.0225 \\
\hline PWR Drift Length, m* & -- & -- & 76.3 & 80.5 \\
\hline Process Waste Drift length, $\mathrm{m}$ & -- & -- & 0.7 & 0.7 \\
\hline GT-MHR Drift length, m & 66.7 & 17.5 & 44.4 & 44.4 \\
\hline Benefit relative to first row & 1.13 & 4.18 & 1.69 & 1.78 \\
\hline
\end{tabular}

* Producing the same amount of energy as 77 MTIHM of PWR fuel and 1 MTIHM of DB-MHR fuel.

Preliminary indications are that $\mathrm{SiC}$ will likely have a higher dissolution rate than pyrolytic carbon and that pyrolytic carbon dissolution rates are likely to be somewhat larger than graphite dissolution rates. Measured temperature dependence is, so far, consistent with a single activation mechanism and an Arrhenius empirical form. Measured degradation rates for SiC are more than an order of magnitude lower and in most cases more than two orders of magnitude lower than the rates for borosilicate glass and may follow a similar "v-shaped" dependence on $\mathrm{pH}$.

A computer model accounting for the failure of waste packages, the dissolution of the fuel assembly blocks, the fuel compacts, and the pyrolytic carbon and $\mathrm{SiC}$ coatings on the TRISO fuel particles was used to assess the impact of various values of the dissolution rates in a repository. These calculations considered the ability of the fuel assembly blocks, fuel compacts, and particle coatings to protect radionuclide-containing fuel kernels from water as individual barriers forming a defense-in-depth. Several million years of defense are provided by the fuel assembly blocks, themselves, if they remain impermeable with dissolution rates up to $\sim 10^{-3}$ $\mathrm{g} / \mathrm{m}^{2} / \mathrm{yr}$. Once the assembly block barrier is breached the fuel compacts will begin to expose fuel particles as soon as they begin to dissolve, but with graphite dissolution rates in the range between $10^{-4}$ and $10^{-5} \mathrm{~g} / \mathrm{m}^{2} / \mathrm{yr}$, the fraction of kernels exposed to water can be restricted to a few percent for between one and ten million years. Finally, if the dissolution rates for either the pyrocarbon or the $\mathrm{SiC}$ layers are $10^{-5} \mathrm{~g} / \mathrm{m}^{2} / \mathrm{yr}$ or lower, the particle coatings alone could prevent water from contacting the fuel kernels for several million years. SiC (the middle layer of the TRISO fuel particle coating) dissolution rates at $30{ }^{\circ} \mathrm{C}$ could be as low as $10^{-5} \mathrm{~g} / \mathrm{m}^{2} / \mathrm{yr}$, but most measured values are at least an order of magnitude higher than this value. Extrapolation of measured data in deionized water indicate that dissolution rates for graphite (fuel assembly blocks and fuel compacts) at $30{ }^{\circ} \mathrm{C}$ are close to $10^{-5} \mathrm{~g} / \mathrm{m}^{2} / \mathrm{yr}$. More recent measurements for graphite powder span a range of values from $10^{-5} \mathrm{~g} / \mathrm{m}^{2} / \mathrm{yr}$ up to $10^{-2} \mathrm{~g} / \mathrm{m}^{2} / \mathrm{yr}$ with the lower part of the range more likely applicable to Yucca Mountain Repository conditions. Most of the 
dissolution rate data for pyrolytic carbon (inner and outer coatings on the TRISO fuel particles) are in the range between graphite and $\mathrm{SiC}$, but closer to the graphite values.

Based on thermal calculations, the scheme of recycling heat-generating actinides from spent PWR fuel as new TRISO fuel in a DB-MHR results in a relatively small repository space utilization benefit factor (ranging from 1.7 to 1.8) over simply generating energy in PWRs and disposing spent fuel directly. The reason is (as in all cases of limited recycle in thermal reactors studied) most recycled isotopes that generate long-term decay heat are not burned efficiently, but simply end up being directly disposed after the last recycle. Consideration was also given to the physical space occupied by directly disposed TRISO fuel assemblies and compacts. Removal of the fuel compacts from the fuel assembly blocks and placing them in the waste packages would allow the repository benefit determined by the thermal calculations to be achieved. However, if the DB-MHR fuel is disposed within the fuel assembly blocks and if the blocks are placed in waste package having the same volume as the 21-PWR waste packages currently considered for the repository, then even the modest benefit indicated by the thermal calculations may not be achievable.

\section{References}

1. "Gas Turbine-Modular Helium Reactor (GT-MHR) Conceptual Design Description Report," General Atomics, 910720 Rev. 1 (July 1996).

2. "Total System Performance Assessment for the Site Recommendation," TDR-WIS-PA000001 REV 00 ICN 01 (December 2000).

3. Gert F. Eriksen and Karsten Dyrbye, "Protective Coatings in Harsh Environments," Journal of Micromechanics and Microengineering, 6, pp. 55-57 (1996).

4. Douglas W. Freitag and David W. Richerson, "Opportunities for Advanced Ceramics to Meet the Needs of the Industries of the Future," DOE/ORO 2076 (December 1998).

5. W. J. Gray, "A Study of the Oxidation of Graphite in Liquid Water for Radioactive Waste Storage Applications," Radioactive Waste Management and the Nuclear Fuel Cycle, 3(2), pp. 137-149 (December 1982).

6. Frank Carre, Jean-Claude Gauthier, and Dominique Hittner, Viewgraph Presentation, Idaho Falls, Idaho (July 6-7,2005).

7. Viewgraph Presentation from European Union, Personal Communication from Francesco Venneri (August 2005).

8. Matt Richards, "Review of Argonne National Laboratory's Assessment of TRISOCoated Fuel Performance in a Geologic Repository," Memorandum to F. Venneri (July 6, 2005).

9. T. K. Kim, Personal Communication (August 2005). 


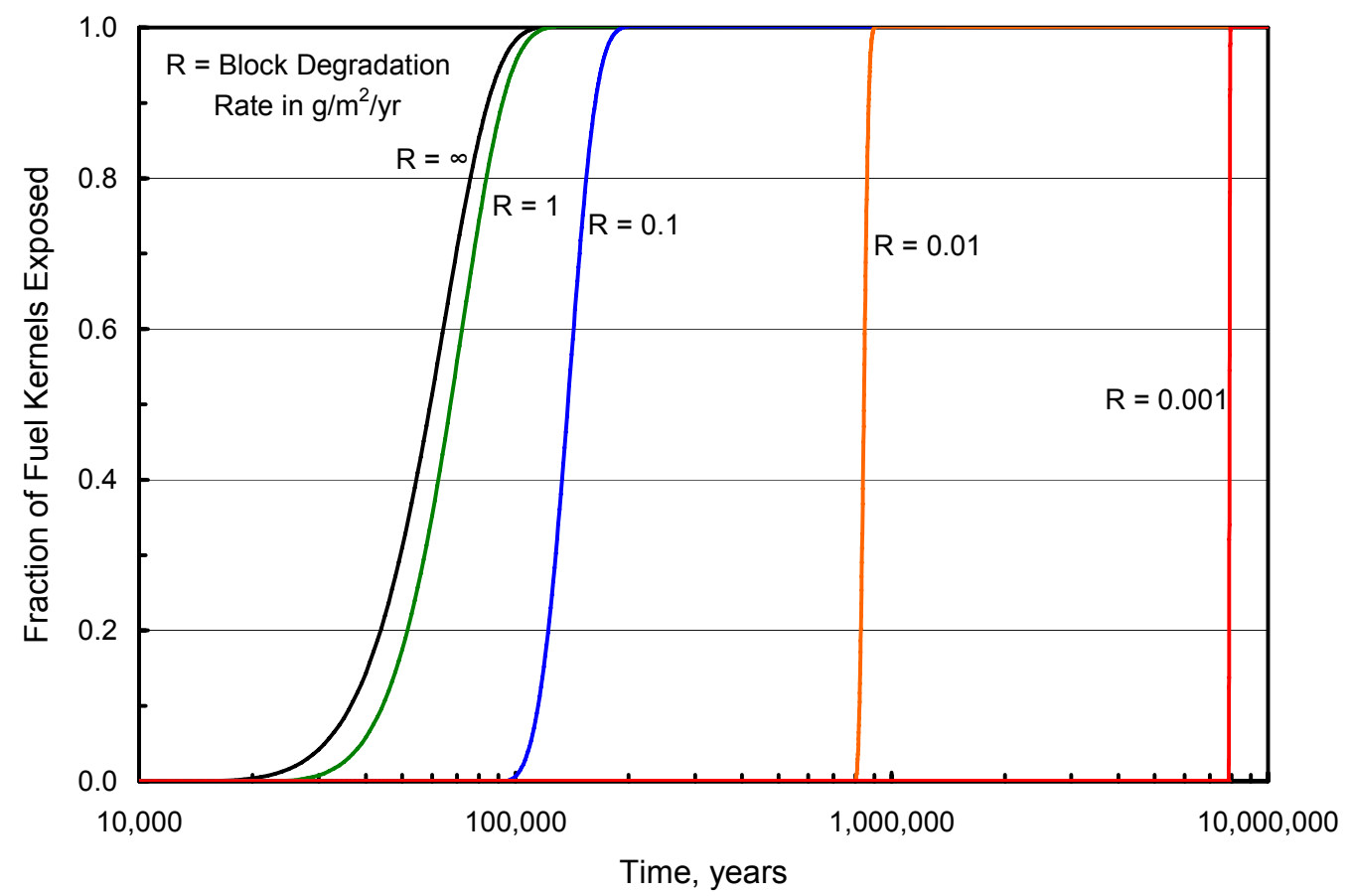

Fig. 5. Fraction of fuel kernels exposed to water when protected only by the waste package and the fuel assembly blocks.

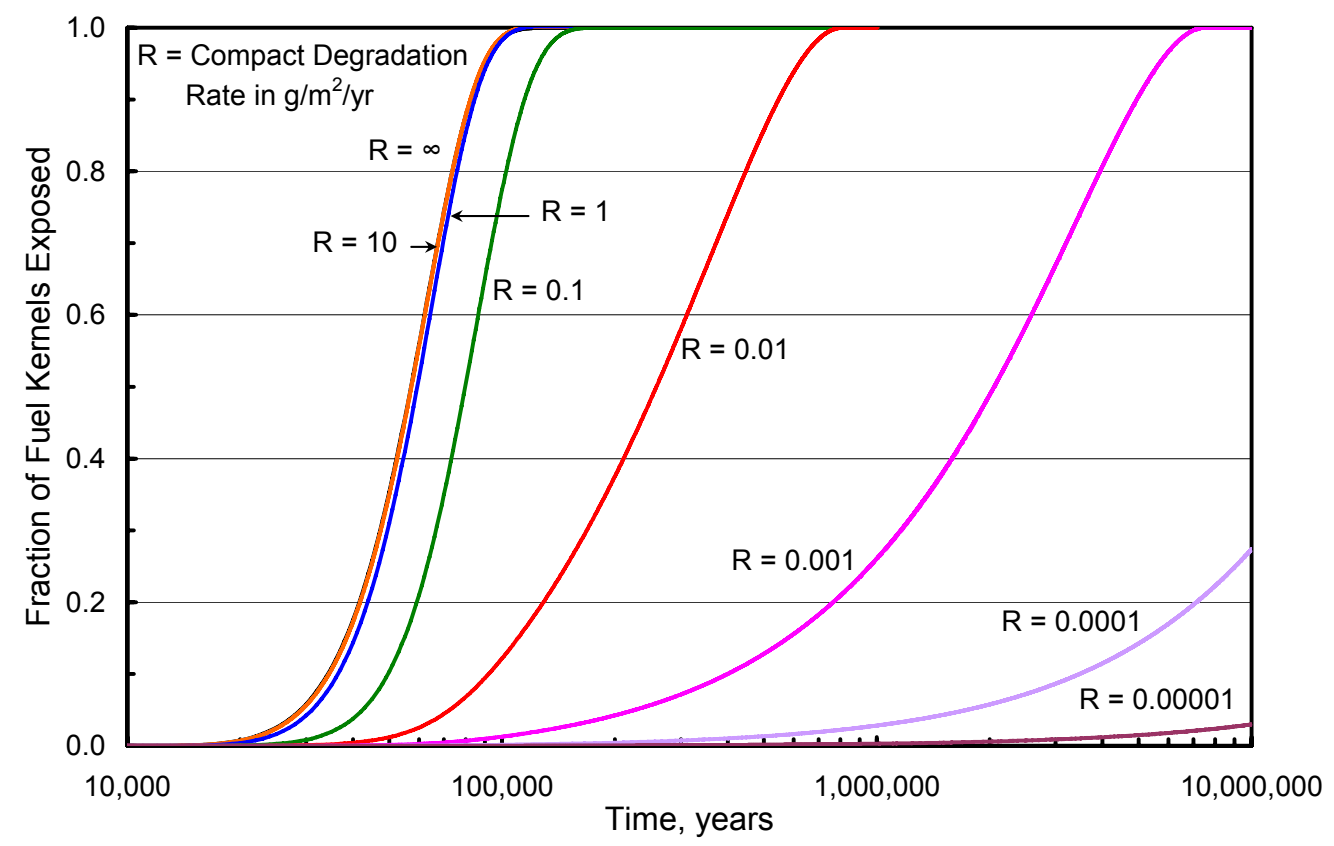

Fig. 6 Fraction of fuel kernels exposed to water when protected only by the waste package and the fuel compacts. 


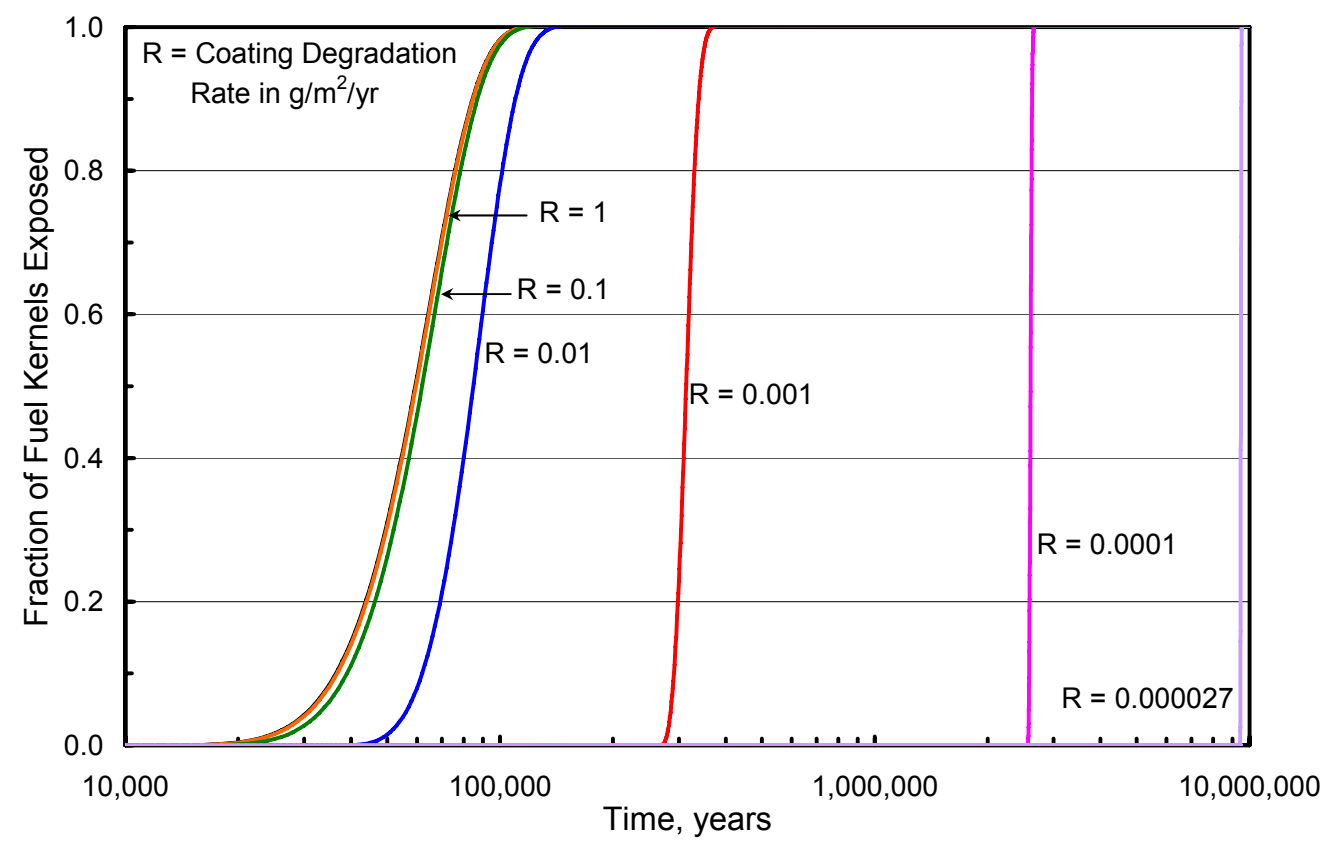

Fig. 7. Fraction of fuel kernels exposed to water when protected only by the waste package and the fuel particle coatings.

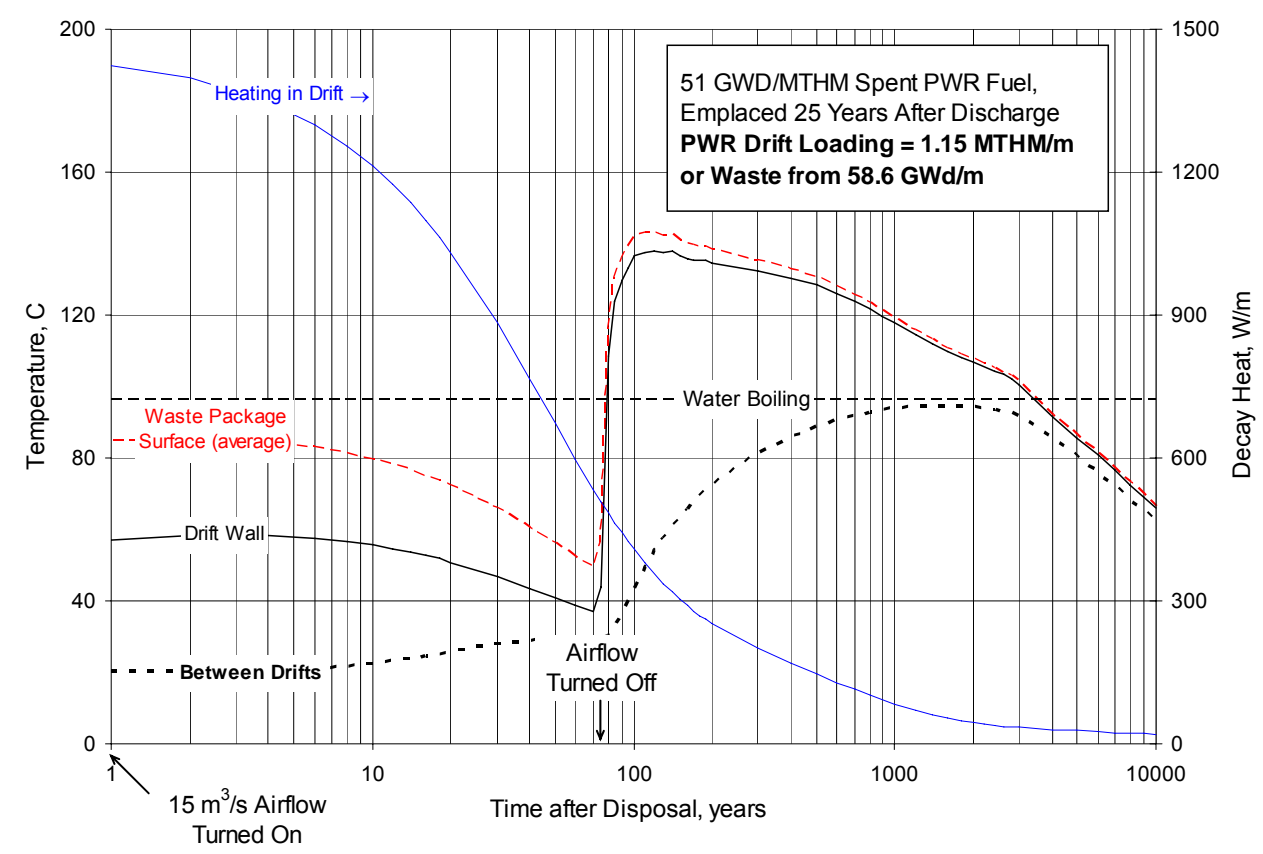

Fig. 8. Selected temperatures for drifts containing spent PWR fuel. 
Maximal Waste Package Loading in Drifts (HTOM)

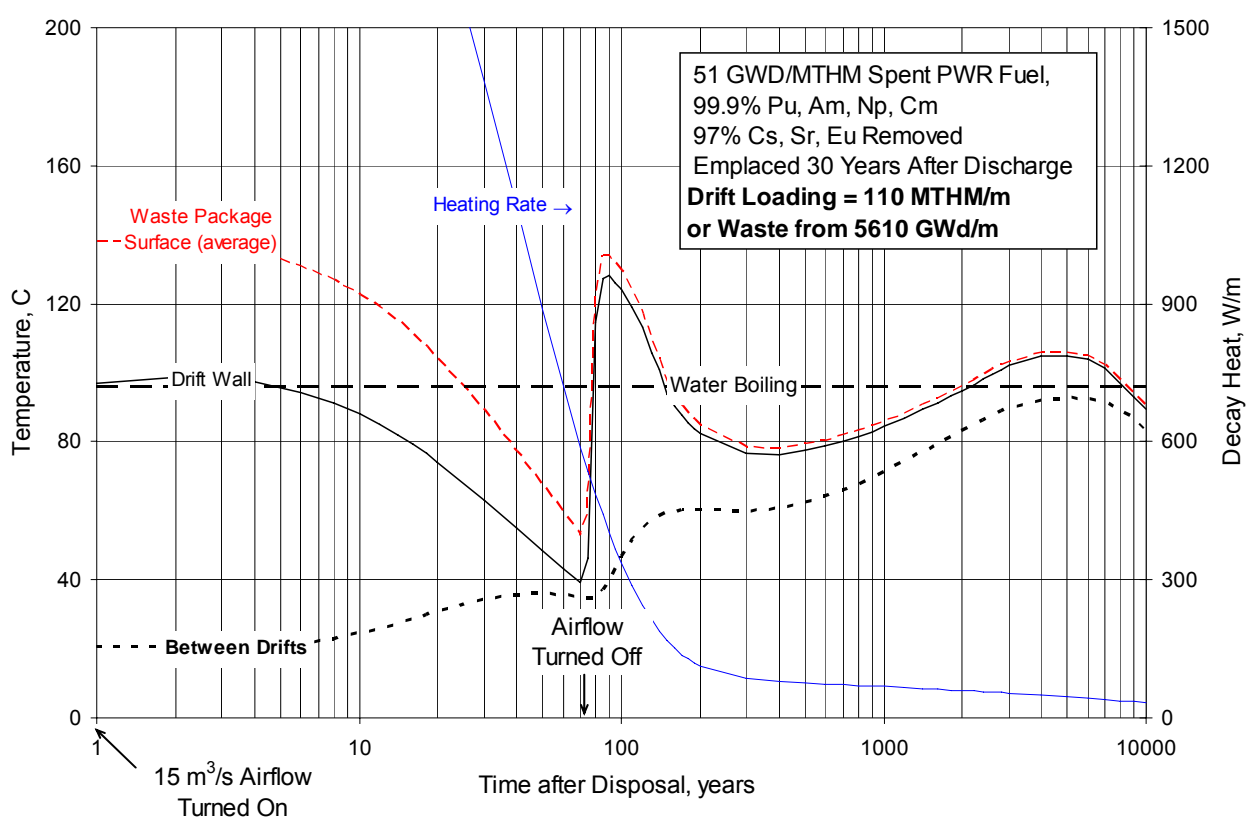

Fig. 9. Selected temperature for drifts filled with process waste from spent PWR fuel.

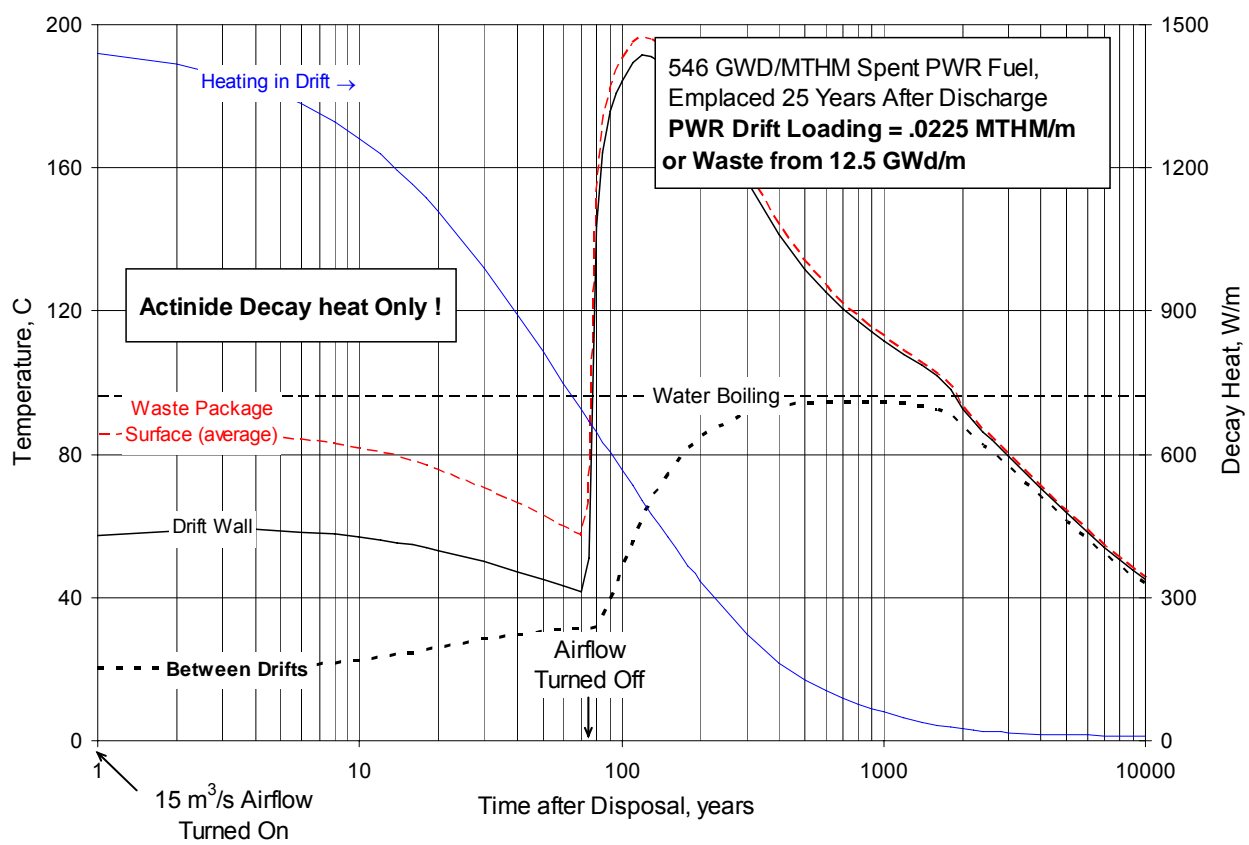

Fig. 10. Selected temperatures for drifts filled with spent DB-MHR fuel. 